\title{
Comparing a standard and tailored approach to scaling up an evidence-based intervention for antiretroviral therapy for people who inject drugs in Vietnam: study protocol for a cluster randomized hybrid type III trial
}

Minh X. B. Nguyen ${ }^{1,2^{*}}$ D, Anh V. Chu ${ }^{3}$, Byron J. Powell ${ }^{4}$, Ha V. Tran ${ }^{1,3}$, Long H. Nguyen ${ }^{5}$, An T. M. Dao², Manh D. Pham ${ }^{5}$, Son H. Vo ${ }^{5}$, Ngoc H. Bui ${ }^{2}$, David W. Dowdy ${ }^{6}$, Carl A. Latkin ${ }^{7}$, Kathryn E. Lancaster ${ }^{8}$, Brian W. Pence ${ }^{9}$, Teerada Sripaipan ${ }^{1}$, Irving Hoffman ${ }^{10}$, William C. Miller ${ }^{8}$ and Vivian F. Go ${ }^{1 *}$

\begin{abstract}
Background: People who inject drugs (PWID) bear a disproportionate burden of HIV infection and experience poor outcomes. A randomized trial demonstrated the efficacy of an integrated System Navigation and Psychosocial Counseling (SNaP) intervention in improving HIV outcomes, including antiretroviral therapy (ART) and medications for opioid use disorder (MOUD) uptake, viral suppression, and mortality. There is limited evidence about how to effectively scale such intervention. This protocol presents a hybrid type III effectiveness-implementation trial comparing two approaches for scaling-up SNaP. We will evaluate the effectiveness of SNaP implementation approaches as well as cost and the characteristics of HIV testing sites achieving successful or unsuccessful implementation of SNaP in Vietnam.
\end{abstract}

Methods: Design: In this cluster randomized controlled trial, two approaches to scaling-up SNaP for PWID in Vietnam will be compared. HIV testing sites $(n=42)$ were randomized 1:1 to the standard approach or the tailored approach. Intervention mapping was used to develop implementation strategies for both arms. The standard arm will receive a uniform package of these strategies, while implementation strategies for the tailored arm will be designed to address site-specific needs. Participants: HIV-positive PWID participants $(n=6200)$ will be recruited for medical record assessment at baseline; of those, 1500 will be enrolled for detailed assessments at baseline, 12, and 24 months. Site directors and staff at each of the 42 HIV testing sites will complete surveys at baseline, 12, and 24 months.

* Correspondence: binhminh@live.unc.edu; vgo@live.unc.edu

'Department of Health Behavior, Gillings School of Global Public Health, 135 Dauer Dr, Chapel Hill, NC 27599, USA

Full list of author information is available at the end of the article

C The Author(s). 2020 Open Access This article is licensed under a Creative Commons Attribution 4.0 International License, which permits use, sharing, adaptation, distribution and reproduction in any medium or format, as long as you give appropriate credit to the original author(s) and the source, provide a link to the Creative Commons licence, and indicate if changes were made. The images or other third party material in this article are included in the article's Creative Commons licence, unless indicated otherwise in a credit line to the material. If material is not included in the article's Creative Commons licence and your intended use is not permitted by statutory regulation or exceeds the permitted use, you will need to obtain permission directly from the copyright holder. To view a copy of this licence, visit http://creativecommons.org/licenses/by/4.0/. The Creative Commons Public Domain Dedication waiver (http://creativecommons.org/publicdomain/zero/1.0/) applies to the data made available in this article, unless otherwise stated in a credit line to the data. 
(Continued from previous page)

Outcomes: Implementation outcomes (fidelity, penetration, acceptability) and effectiveness outcomes (ART, MOUD uptake, viral suppression) will be compared between the arms. To measure incremental costs, we will conduct an empirical costing study of each arm and the actual process of implementation from a societal perspective. Qualitative and quantitative site-level data will be used to explore key characteristics of HIV testing sites that successfully or unsuccessfully implement the intervention for each arm.

Discussion: Scaling up evidence-based interventions poses substantial challenges. The proposed trial contributes to the field of implementation science by applying a systematic approach to designing and tailoring implementation strategies, conducting a rigorous comparison of two promising implementation approaches, and assessing their incremental costs. Our study will provide critical guidance to Ministries of Health worldwide regarding the most effective, cost-efficient approach to SNaP implementation.

Trial registration: NCT03952520 on Clinialtrials.gov. Registered 16 May 2019.

Keywords: Implementation science, Implementation strategies, Tailoring implementation strategies, Intervention mapping, People who inject drugs, Vietnam, HIV, System navigation, Psychosocial counseling, Intervention, Cost-effectiveness, Economic evaluation

\section{Contributions to the literature}

- The proposed study uses rigorous methods, including intervention mapping, to design implementation strategies for an integrated intervention targeting PWID living with HIV in Vietnam. It compares a standard and a tailored approach to scaling up the intervention at the national level.

- This study allows for assessments of the incremental costs of the standard versus tailored approach to implementation. Our cost-effectiveness analyses incorporate prospective, empirical costing of the full implementation process (including all aspects of intervention mapping), not just the intervention itself.

- To inform future scale-up, we will focus on HIV test site-level predictors of successful implementation. These data will provide insight into site characteristics that influence EBI implementation among PWID, thereby informing governments' decisions about the allocation of limited resources.

\section{Background}

People who inject drugs (PWID) bear a disproportionate burden of HIV infection. Globally, approximately 1.4 million PWID live with HIV, and the prevalence of HIV among PWID has been estimated to be $12.7 \%$ [1]. PWID with HIV have high mortality rates compared with their non-drug using counterparts [2]. The mortality difference is largely driven by delayed diagnosis, low uptake, and adherence to antiretroviral therapy (ART) [3]. Most PWID have not been tested for HIV; in some geographic areas, less than $2 \%$ of PWID have been tested [4]. In countries with available data, ART coverage among HIV-positive PWID is only 5-67\% of PWID living with HIV [1]. PWID lack access to HIV care, medications for opioid use disorder (MOUD), and harm reduction services and limited skills to navigate complex health care systems [4-8]. They also face persistent social barriers, such as stigma and punitive legal systems [5].

Vietnam is a prime country example of an HIV epidemic that has been primarily driven by injection drug use. Vietnam has over 271,000 PWID in the country [9] with an HIV prevalence among PWID in different provinces ranging from 17 to $25 \%$ [10-12]. In 2014, the 90-9090 targets were launched by the Joint United Nations Programme on HIV/AIDS: $90 \%$ of all people living with HIV will know their HIV status; $90 \%$ of all people with diagnosed HIV infection will receive sustained antiretroviral therapy, and $90 \%$ of all people receiving antiretroviral therapy will have viral suppression [13]. Vietnam was the first Asian country to commit to the World Health Organization's 90-90-90 targets [14], but reaching these targets will require significant efforts to prevent and treat HIV among PWID. Moreover, since funding from international donors for HIV research has dramatically decreased within the last few years $[15,16]$, it is even more critical for the Vietnamese government to implement effective and cost-efficient HIV interventions.

From 2015 to 2018, we conducted the HIV Prevention Network Trial 074. (HPTN074) - a multi-site study to evaluate the feasibility and efficacy of an integrated systems navigation and psychosocial counseling ( $\mathrm{SNaP}$ ) intervention for HIV-positive PWID on ART use, viral suppression, and MOUD use in Vietnam, Indonesia, and Ukraine [17]. Among PWID with HIV, SNaP led to marked improvements in ART uptake and use, viral suppression, MOUD uptake and use, and mortality [17]. SNaP has potential to curb the epidemic among PWID, but first it needs to be scaled-up to reach a broader population.

Scaling-up evidence-based interventions (EBIs) is often impeded by barriers at different levels, such as 
constrained budgets, lack of support policies, lack of qualified leaders, and staff as well as cultural resistance to new practice $[18,19]$. In reality, EBIs such as $\mathrm{SNaP}$ often languish on a shelf or are implemented without careful consideration of barriers in routine care settings [20]. Many countries have recently scaled-up HIV testing and counseling and ART throughout their countries $[4,6]$ using national level decrees $[5,7]$. This top-down, one-size-fits-all decree approach successfully reached many people with HIV [21-23] but has failed to reach PWID [4, 21-23]. The limited success among PWID may be because the national implementation strategy does not address key country-wide barriers or because the implementation approach failed to consider variation by risk groups and clinics. For example, despite the welldocumented effectiveness of EBIs such as needle/syringe programs and opioid substitution treatment, the coverage of these EBIs still remained very low among PWID in many parts of the world [4]. This is partly due to policing practices and laws criminalizing drug use and possession implemented by local authorities, which could vary by country, state, or even city [24].

There is a need to identify and evaluate systematic approaches to scaling-up and sustaining EBIs such as $\mathrm{SNaP}$ $[19,25,26]$, as the best approach to implementing and scaling up such efficacious interventions for PWID in real-world settings is unclear [4, 20]. Scaling-up EBIs will likely require the use of multiple implementation strategies that effectively address multi-level determinants (i.e., barriers and facilitators) of implementation and scale-up [27-29]. Implementation strategies are "methods or techniques used to enhance the adoption, implementation, sustainment, or scale-up of interventions" [28]. The lack of systematic approaches to developing implementation strategies can lead to failed implementation efforts and make them difficult to replicate in other settings [30,31]. A number of approaches that integrate theory, evidence, and relevant stakeholder perspectives to systematically design and tailor implementation strategies have been identified [32, 33], including intervention mapping (IM) [3436]. Recent guidance clarifies IM's role in implementation science by describing how it can be used to adapt interventions and develop implementation strategies [34], and a study underway is examining its potential utility as a method for tailoring implementation strategies at the organizational level [25].

IM applied at the national level may suffice to produce an appropriate national implementation package for $\mathrm{SNaP}$ scale up. But implementation determinants at specific HIV testing sites may impede this approach. Thus, it may be useful to apply methods that will help to tailor implementation approaches to address site-specific needs. Tailoring strategies to address contextual needs has face validity [37] and has been shown to be effective at improving health practices [38], but rigorous evaluations that test methods for tailoring strategies and compare tailored and standard multifaceted strategies are needed [28, 32, 38, 39]. Moreover, since the scale up of interventions might be costly and various interventions usually compete for resources and attention from stakeholders [40], evidence of the costs in conjunction with effectiveness of implementation approaches is also required, especially in settings where resources are limited. However, the quantity and quality of economic evaluations of implementation studies remain inadequate [40, 41]. In a systematic review and critical appraisal of health economic methods in implementation research, only $3(10 \%)$ among all studies included were conducted in low- and middle-income countries [40].

To close these gaps, this cluster randomized trial will compare a standard multifaceted approach to implementation to a tailored approach that involves the identification of sitespecific determinants combined with implementation facilitation that will help sites identify and apply appropriate implementation strategies. We hypothesize that, compared to the standard approach, the tailored approach will (a) increase site fidelity to SNaP, (b) increase ART uptake among PWID, and (c) be cost-effective. Our specific aims are the following:

1. To compare the standard approach with the tailored approach for scaling-up the integrated intervention, SNaP, for PWID in HIV testing sites in Vietnam.

2. To measure the incremental costs of the standard approach compared with the tailored approach for $\mathrm{SNaP}$ implementation in Vietnam.

3. To explore the key characteristics of high- and lowperforming HIV testing sites for $\mathrm{SNaP}$ implementation in each study arm.

In this protocol paper, we present the conceptual framework, study design, and randomization scheme of the study. We also describe the participants, intervention approaches, outcomes, data collection, and analysis. Finally, we discuss the strengths and weaknesses of the trial, as well as the priorities in the field of implementation science that it addresses. We followed the STARi checklist for implementation intervention [42] and the CONSORT checklist for cluster randomized controlled trial [43] (Additional file 1).

\section{Methods}

\section{Guiding conceptual frameworks}

As specified in the conceptual framework (Fig. 1), both standard and tailored implementation approaches are expected to have an effect on $\mathrm{SNaP}$ implementation. High acceptability, fidelity, penetration of SNaP implementation will lead to better effectiveness outcomes such as ART uptake, MOUD uptake, and viral 


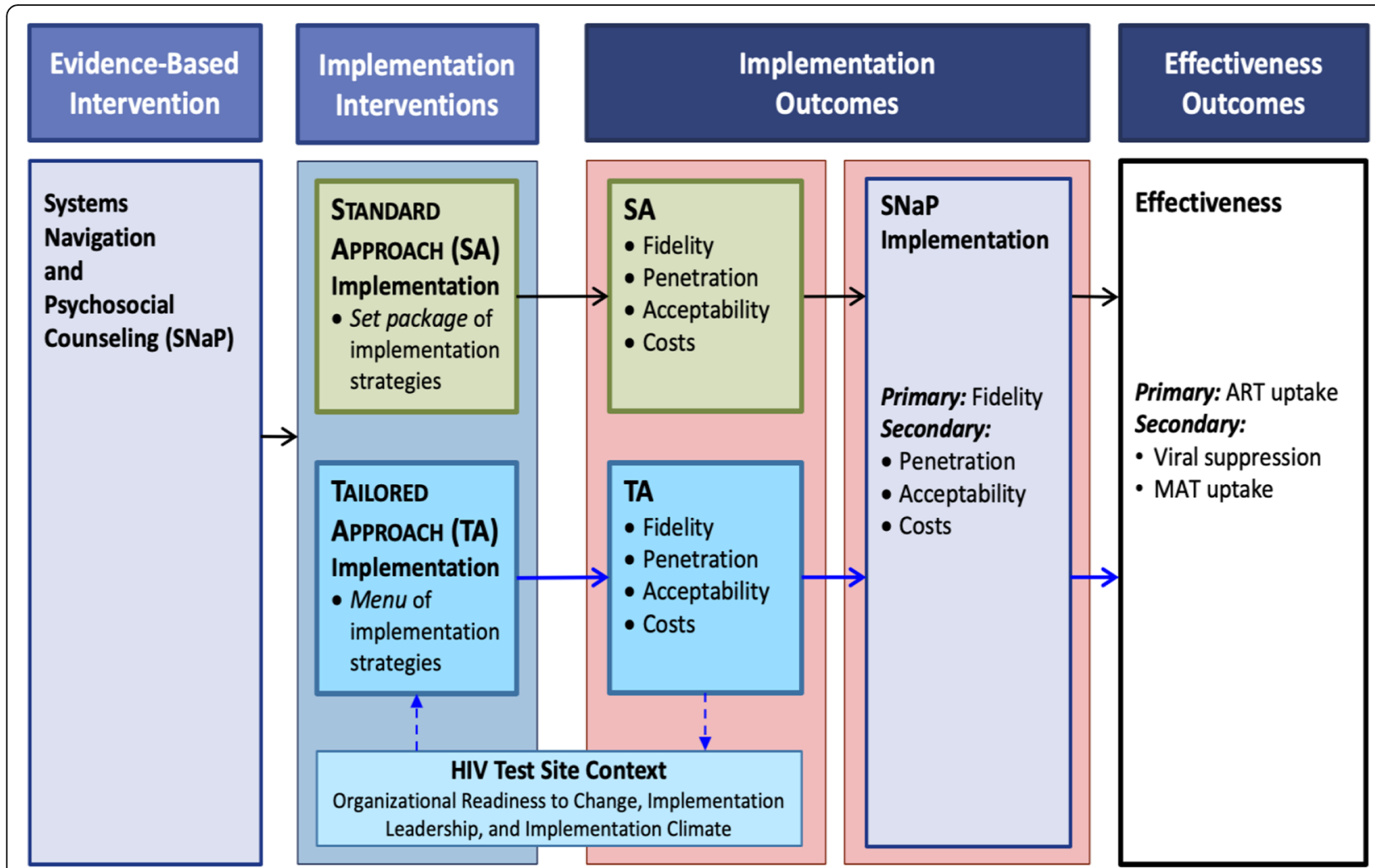

Fig. 1 Conceptual framework (adapted from Proctor's framework [44])

suppression. The study is guided by conceptual frameworks to inform implementation processes (intervention apping) [36], identify implementation barriers, and facilitators (Consolidated Framework for Implementation Research; CFIR) [45], and assess implementation outcomes $[44,46]$. IM provides a systematic process to yield standard and tailored approaches to implementation. CFIR is a comprehensive framework that identifies 39 different factors in five domains that influence implementation outcomes. In this study, we focus primarily on one of the five CFIR domains, the "inner setting," defined as the clinic or organizational context in which the intervention will exist [47]. We will measure the inner setting characteristics that influence implementation of $\mathrm{SNaP}$ and are likely to vary across sites. These include the age and size of the test site; norms of the test site; organizational readiness to change; implementation leadership, and implementation climate [45, 48-51]. We hypothesize that tailoring implementation strategies to address test site context will improve test site context and lead to better implementation and effectiveness outcomes. The implementation outcomes framework [44] guides our assessment of key implementation outcomes: acceptability, fidelity, penetration, and cost. The effectiveness of $\mathrm{SNaP}$ scale-up will be assessed by the implementation processes as operationalized through both arms. As depicted in the conceptual framework (Fig. 1), these implementation outcomes are in relation to both implementation approaches and $\mathrm{SNaP}$ itself. First, the two implementation approaches must be acceptable to stakeholders and implemented well (e.g., with fidelity), which in turn, affects $\mathrm{SNaP}$ implementation. Second, successful implementation of $\mathrm{SNaP}$, with high fidelity, penetration, and acceptability will lead to better effectiveness outcomes (ART uptake).

\section{Study design}

This is a hybrid type III study that has a dual focus on effectiveness and implementation outcomes [52]. We will conduct a cluster randomized controlled trial in 42 HIV testing sites in 10 Vietnamese provinces with high HIV prevalence among PWID. HIV testing sites are the unit of randomization. The sites will receive either standard or tailored approach with 1:1 allocation to each study arm (Fig. 2).

\section{Randomization}

During the pre-implementation phase, we conducted inperson site visits, where we evaluated the strength of leadership commitment at each site through observation and communication with site leaders. Based on a brief qualitative description of leaders' engagement and 


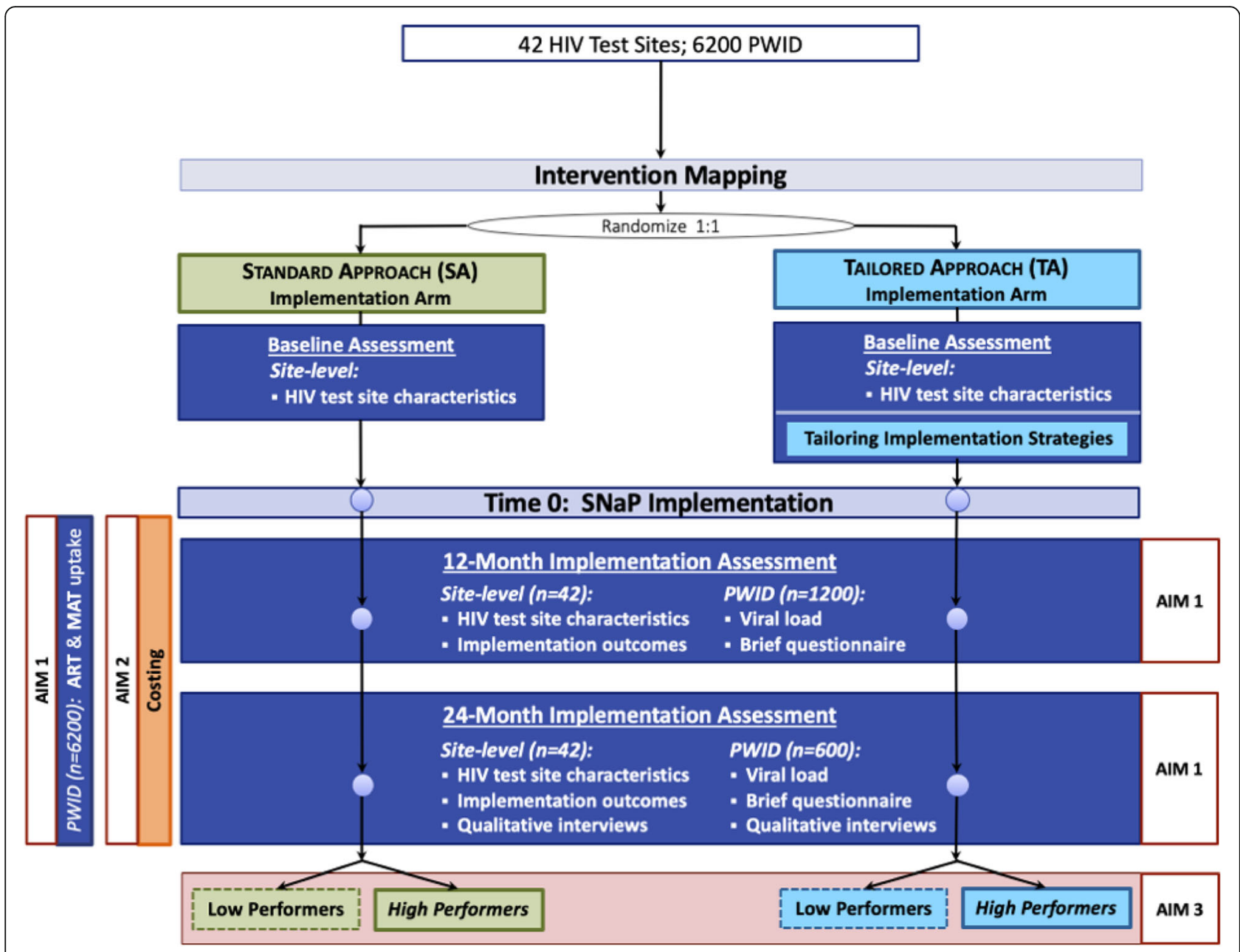

Fig. 2 Study design overview and randomization scheme

willingness to participate in $\mathrm{SNaP}$, the strength of leadership commitment was classified as either weak or strong. Clinics were then randomly allocated to the two arms at a 1:1 ratio (21 sites per trial arm), stratified by strength of leadership commitment (weak vs. strong). Random allocation was implemented by study statisticians, who used a random number generator to assign each clinic to an arm at a single point in time. Concealment was not used. Randomization results will be masked to data managers, statistical analysts, and staff who collect and/or manage data on the implementation, effectiveness, and costing outcomes. Randomization was conducted before enrolling participants and asking them to provide informed consent.

\section{Participants}

\section{HIV testing sites}

We obtained a complete list of the 136 HIV testing sites in Vietnam from the Vietnam Authority of AIDS Control (VAAC), including the number of persons tested per month, positivity rates, and proportion of PWID clients. These data were used to identify proposed HIV testing sites for inclusion in this implementation study. Fortytwo HIV testing sites in 10 provinces with the highest PWID HIV prevalence were chosen by the study team. The list of HIV testing sites was reviewed and approved by provincial departments of health and the Vietnam Ministry of Health. The ten selected provinces are located across Vietnam and include Dien Bien, Son La, Thai Nguyen, Phu Tho, Ha Noi, Quang Ninh, Nghe An, Khanh Hoa, Ho Chi Minh City, and Long An.

\section{PWID participants}

Following Vietnam's national HIV testing algorithm, people with positive rapid test results have their diagnosis confirmed at the nearest $\mathrm{MOH}$-certified confirmatory laboratory, using the standard confirmation HIV test [53]. In this study, eligible PWID participants at chosen HIV testing sites must test positive using the standard confirmatory test; be 18 years or older; report a history 
of injection drug use in the past 6 months; live in the HIV treatment catchment area and be willing to provide informed consent. The total duration of recruitment is 18 months. Up to $6200 \mathrm{HIV}$-positive participants will be recruited for medical record assessment at baseline. Of those, 4700 will be asked to provide consent only for medical record assessment and will not be re-contacted. The remaining 1500 participants will be enrolled in a subsample cohort for detailed assessments at baseline, 12 , and 24 months, including questionnaires and viral load determination. The sub-sample will be re-contacted for interview and assessment of viral suppression 6-12 months after site implementation. The group enrolled in the first 12 months after site implementation will also have 18-24-month assessments.

\section{HIV test site directors and staff}

Eligible participants include directors, navigators, counselors, and other staff at HIV testing sites who are willing to provide consent. Six staff at each site will be enrolled and asked to complete brief quantitative surveys at preimplementation, 12, and 24 months post-implementation. These surveys will be administered online to assess site context measurements, including organizational readiness to change, implementation leadership, and implementation climate. Organizational readiness to change will be measured using the Organizational readiness for implementing change scale-a 12-item scale that evaluates readiness for implementation [54]. Implementation leadership will be measured with the Implementation Leadership Scale, which assesses four dimensions of leadership in EBI implementation: being proactive, knowledgeable, supportive, and perseverant [55]. Implementation climate will be measured using the 18-item Implementation Climate Scale, which evaluates support, recognition, selection, and rewards for innovation use [55] (Additional file 2).

\section{Interventions \\ Evidence-based intervention: systems navigation and psychosocial counseling (SNaP)}

At the individual level, all PWID with confirmed HIV infection at the HIV testing sites will receive the $\mathrm{SNaP}$ integrated intervention that has been demonstrated to be effective in HPTN 074 [17]. The intervention was originally designed by the study team to increase engagement in HIV and substance use treatment among PWID [56]. In this study, the $\mathrm{SNaP}$ intervention was modified slightly in accordance with the changes in the healthcare system and HIV policies in Vietnam since the HPTN 074 study, such as the merging of district health centers into district hospitals, or payment of HIV care through health insurance instead of international donor funding. Moreover, to increase the feasibility of scaling up, the contents of the original two counseling sessions were combined into one required session only. The intervention has two components: (1) systems navigation to facilitate engagement and retention in HIV care and MOUD (currently methadone in Vietnam), and to negotiate required laboratory tests (e.g. CD4 counts) or transportation; and (2) psychosocial counseling using motivational interviewing, problem solving, skills building, and goal setting to facilitate ART and MOUD initiation and adherence. Systems navigators will initially meet participants twice, in-person or by telephone, within 8 weeks of enrollment. Psychosocial counselors will provide participants with a minimum of one counseling session within 4 weeks of enrollment, with the first session preferably during post-test counseling. To determine the need for additional sessions, the counselor will use a standardized inventory to assess the participants' need for counseling on risk reduction, drug treatment entry and retention, HIV medical care, ART and MOUD adherence, depression, alcohol dependence, and social support. Participants will be offered the opportunity for additional booster sessions, if needed, at about 1 and 3 months after enrollment.

\section{Process for developing implementation strategies}

IM can help improve the design of implementation strategies by incorporating theory, evidence, and stakeholder perspectives to ensure that strategy components effectively address key barriers to change [34]. In this study, we used IM to create a menu of standard implementation strategies selected to be applied to all 42 sites (i.e., the standard implementation package).

The study team worked with local stakeholders to conduct IM through the following steps:

1) Step 1: state outcomes (e.g., implementation outcomes such as fidelity, penetration, acceptability, and costs; effectiveness outcomes such as ART uptake, viral suppression, and MOUD uptake) and performance objectives (e.g., who needs to do what to implement and sustain $\mathrm{SNaP}$ ).

2) Step 2: identify determinants (barriers and facilitators) of implementation through data from HPTN 074's qualitative data and formative research, including focus group discussions, and informal interviews with local stakeholders and site visits.

3) Step 3: identify appropriate implementation strategies that can potentially help to address identified determinants and achieve performance objectives, using previously published compilations of implementation strategies and a structured brainstorming process. 
Table 1 Characteristics of standard implementation strategies (applied to all sites)

\begin{tabular}{|c|c|c|c|}
\hline No & Strategy & Actor(s) & Action ${ }^{\gamma}$ \\
\hline 01 & $\begin{array}{l}\text { Organize a meeting with } \\
\text { leaders of the Vietnam } \\
\text { Authority of HIV/AIDS } \\
\text { Control (VAAC) to introduce } \\
\text { SNaP }\end{array}$ & $\begin{array}{l}\text { - The central } \\
\text { research } \\
\text { team* }\end{array}$ & $\begin{array}{l}\text { - Prepare resources and } \\
\text { organize a meeting with } \\
\text { VAAC to introduce SNaP } \\
\text { and discuss collaboration }\end{array}$ \\
\hline
\end{tabular}

Action target

\begin{tabular}{ll} 
Dose & Timing \\
\hline Once & $\begin{array}{l}\text { Before SNaP } \\
\text { implementation }\end{array}$ \\
& \\
Annually & $\begin{array}{l}\text { Beginning of each } \\
\text { year of the study }\end{array}$ \\
& \\
& \\
Once & $\begin{array}{l}\text { Before SNaP } \\
\text { implementation }\end{array}$
\end{tabular}

02 Develop and share a timeline and plan for field activities annually with VAAC and Hanoi Medical University (HMU) - two local collaborators in Vietnam

03 Collect data on site infrastructures and personnel through site initial assessments

04 Perform initial site visits to introduce $\mathrm{SNaP}$, discuss cooperation mechanism with leaders and staff at provincial and site levels, and identify appropriate personnel for $\mathrm{SNaP}$ implementation
05 Identify a focal point person for each province

$\begin{array}{ll}\text { - The central } & \text { Develop and share annual } \\ \text { research } & \text { implementation plan with } \\ \text { team } & \text { central collaborators and } \\ & \text { stakeholders at VAAC and } \\ & \text { HMU }\end{array}$

- The central research

team

- Site leaders and staff

- The central research

team

- Site leaders and staff

- Complete the assessment and return to central team for analysis (done by site staff)

- Visit provincial Centers for Disease Control (CDCs) and sites participating in the study to build the initial rapport with members of
- VAAC is the governmental organization in charge of HIV/AIDS care in Vietnam and also one of the main collaborators of the study. It is critical that VAAC understands the SNaP intervention and the resources needed for the study at different levels so that they can provide support for the study at the national level

- Stakeholders at VAAC and HMU need to know the timeline and implementation activities of each year as well as their responsibilities, so that they can collaborate well with the central research team to implement SNaP

- Data on site infrastructures and personnel is collected from sites to inform the feasibility of implementation strategies the board of directors and site staff

- Introduce SNaP and receive comments of sites on the implementation of the SNaP

- Discuss the plan for collaboration with the sites to implement SNaP (done by all actors)

- Identify the list of potential staff to participate in launching events, trainings, and SNaP activities

- Explore current routines for antiretroviral therapy (ART) and methadone referral at sites, evaluate sites' resources and willingness to implement SNaP

- Identify appropriate staff of sites to participate in SNaP and seek approval from site leaders (done by all actors)

- The central $\quad$ Visit provincial CDCs and research team - Provincial CDC leaders, site leaders, and staff work with them to identify the focal points of contact for SNaP implementation
- In order to implement SNaP well, site leaders and staff need to understand the nature of the SNaP intervention, design of an implementation study, timeline, budget, human resources needed, and their roles and responsibilities

- Since leadership support is critical to successful implementation of SNaP, provincial and site leaders should be involved in the planning of SNaP and feel empowered

- Appropriate staff of sites is identified to participate in launching events, training events and to implement $\mathrm{SNaP}$

- The central team understands site characteristics needed to implement SNaP in order to design feasible and acceptable implementation strategies

- In order to ensure effective implementation of SNaP at the sites, it is important to identify focal points of contact at each provincial CDCs. They will help with coordinating the intervention at the provincial level.
Once

during site visits

Before $\mathrm{SNaP}$ implementation
Before SNaP implementation 
Table 1 Characteristics of standard implementation strategies (applied to all sites) (Continued)

\begin{tabular}{|c|c|c|c|c|c|c|}
\hline No & Strategy & Actor(s) & Action ${ }^{\gamma}$ & Action target & Dose & Timing \\
\hline 06 & $\begin{array}{l}\text { Establish a community } \\
\text { advisory board consisting } \\
\text { of local stakeholders and } \\
\text { people who infect drugs } \\
\text { (PWID) }\end{array}$ & $\begin{array}{l}\text { - The central } \\
\text { research } \\
\text { team } \\
\text { - Members of } \\
\text { the } \\
\text { community } \\
\text { advisory } \\
\text { board }\end{array}$ & $\begin{array}{l}\text { - Invite the focal points of } \\
\text { contact at provincial CDCs } \\
\text { and representatives of site } \\
\text { staff and PWID in the } \\
\text { community to join the } \\
\text { community advisory board. } \\
\text { - Organize semi-annual meet- } \\
\text { ings with the community } \\
\text { advisory board }\end{array}$ & $\begin{array}{l}\text { - Provincial leaders and site } \\
\text { staff joining the community } \\
\text { advisory board are } \\
\text { motivated to help } \\
\text { coordinate and provide } \\
\text { feedback for SNaP } \\
\text { implementation } \\
\text { - Local stakeholders and the } \\
\text { community of PWID have } \\
\text { the opportunity to voice } \\
\text { their needs and concerns. }\end{array}$ & $\begin{array}{l}\text { Once } \\
\text { before } \\
\text { enrollment } \\
\text { and every } 6 \\
\text { after }\end{array}$ & $\begin{array}{l}\text { Before SNaP } \\
\text { implementation and } \\
\text { every } 6 \text { months after } \\
\text { implementation }\end{array}$ \\
\hline 07 & $\begin{array}{l}\text { Simplify SNaP procedures } \\
\text { to prevent duplicate tasks } \\
\text { for site staff }\end{array}$ & $\begin{array}{l}\text { - The central } \\
\text { research } \\
\text { team }\end{array}$ & $\begin{array}{l}\text { - Explore current routines for } \\
\text { ART and methadone referral } \\
\text { at sites } \\
\text { - Simplify SNaP procedures } \\
\text { to ensure the procedures } \\
\text { are simple to implement } \\
\text { and do not repeat existing } \\
\text { procedures at sites }\end{array}$ & $\begin{array}{l}\text { - Workload burden related to } \\
\text { SNaP is reduced, so that site } \\
\text { staff are more motivated to } \\
\text { implement SNaP }\end{array}$ & Once & $\begin{array}{l}\text { Before } \\
\text { SNaP implementation }\end{array}$ \\
\hline 08 & $\begin{array}{l}\text { Revise the SNaP } \\
\text { intervention manual, taking } \\
\text { into account changes in } \\
\text { the local healthcare } \\
\text { systems, HIV care policies, } \\
\text { and feasibility of scale-up }\end{array}$ & $\begin{array}{l}\text { - The central } \\
\text { research } \\
\text { team }\end{array}$ & $\begin{array}{l}\text { - Collect information on the } \\
\text { structure of the local health } \\
\text { systems and the most } \\
\text { current policies related to } \\
\text { HIV care in Vietnam } \\
\text { - Revise the intervention } \\
\text { manual accordingly and } \\
\text { add new HIV care policies }\end{array}$ & $\begin{array}{l}\text { - The processes of referral } \\
\text { and linking to care are } \\
\text { consistent with the most } \\
\text { current HIV policies and } \\
\text { laws in Vietnam } \\
\text { - The implementation of } \\
\text { SNaP on a large scale is } \\
\text { feasible and acceptable } \\
\text { given the structure and } \\
\text { operation of healthcare } \\
\text { systems at the provincial } \\
\text { and district levels } \\
\text { - Psychosocial counselors and } \\
\text { system navigators are } \\
\text { prepared to help clients } \\
\text { overcome systematic } \\
\text { barriers to accessing HIV } \\
\text { care }\end{array}$ & Once & $\begin{array}{l}\text { Before SNaP } \\
\text { implementation }\end{array}$ \\
\hline
\end{tabular}

09 Conduct regional-level launching events (with VAAC, departments of health, provincial $C D C$ leaders, directors of district health centers)

10 Conduct regional trainings

11 Monthly payment to provincial CDC staff and site staff

\section{- The central • Provide an overview of research team \\ - VAAC \\ leaders, provincial CDC leaders, and site leaders SNaP intervention for local leaders \\ - Give speeches to show local leadership support and willingness to implement SNaP (done by VAAC and local leaders)}

Provide an overview of - All stakeholders understand the nature of SNaP intervention, design of an implementation study, timeline, budget, and human resources needed for the study at sites, so that they motivated to collaborate and implement $\mathrm{SNaP}$.

- Leadership support and political will also motivate site staff to participate in $\mathrm{SNaP}$ and implement SNaP well

- Site staff understands SNaP intervention and their responsibilities. They are also trained to have the necessary skills and knowledge to implement SNaP well at their sites

- The study team provides incentives for provincial CDCs to coordinate SNaP activities at the site level.
Once for At the beginning of each of the SNaP implementation four regions

Once for At the beginning of each of the SNaP implementation four regions

Monthly After enrollment begins research

team

- Focal points to provincial coordination of SNaP activities 
Table 1 Characteristics of standard implementation strategies (applied to all sites) (Continued)

\begin{tabular}{|c|c|c|c|c|c|c|}
\hline No & Strategy & Actor(s) & Action $^{\gamma}$ & Action target & Dose & Timing \\
\hline & & $\begin{array}{l}\text { of provincial } \\
\text { CDC } \\
\text { - System } \\
\text { navigators } \\
\text { and } \\
\text { psychosocial } \\
\text { counselors at } \\
\text { sites }\end{array}$ & $\begin{array}{l}\text { - Provide payment for site } \\
\text { staff for administrative costs } \\
\text { and successful referral of } \\
\text { participants to ART } \\
\text { treatment }\end{array}$ & $\begin{array}{l}\text { - Payment for administrative } \\
\text { costs and successful referral } \\
\text { to ART initiation for } \\
\text { participants are also } \\
\text { provided so that site staff } \\
\text { are motivated to implement } \\
\text { SNaP as intended. }\end{array}$ & & \\
\hline 12 & $\begin{array}{l}\text { Send semi-annual progress } \\
\text { reports of SNaP implemen- } \\
\text { tation to provincial CDCs }\end{array}$ & $\begin{array}{l}\text { - The central } \\
\text { research } \\
\text { team } \\
\text { - Provincial } \\
\text { CDC leaders }\end{array}$ & $\begin{array}{l}\text { - Analyze SNaP progress data } \\
\text { and write up reports } \\
\text { - Share the progress reports } \\
\text { of sites with corresponding } \\
\text { provincial CDCs }\end{array}$ & $\begin{array}{l}\text { - Provincial leaders are } \\
\text { regularly updated on the } \\
\text { progress and results of } \\
\text { SNaP. They can take charge } \\
\text { of coordinating SNaP } \\
\text { activities and providing } \\
\text { continuous leadership } \\
\text { support. }\end{array}$ & $\begin{array}{l}\text { Semi- } \\
\text { annually }\end{array}$ & $\begin{array}{l}\text { Every } 6 \text { months after } \\
\text { enrollment }\end{array}$ \\
\hline 13 & $\begin{array}{l}\text { Integrate plans to address } \\
\text { turnover, such as replacing } \\
\text { and re-training for new staff }\end{array}$ & $\begin{array}{l}\text { - The central } \\
\text { research } \\
\text { team } \\
\text { - Site leaders } \\
\text { and staff }\end{array}$ & $\begin{array}{l}\text { - Inform the central research } \\
\text { team of staff turnover and } \\
\text { replacement (done by site } \\
\text { leaders and staff) } \\
\text { - Conduct training for new } \\
\text { staff }\end{array}$ & $\begin{array}{l}\text { - The central research team } \\
\text { needs to be properly } \\
\text { informed of turnover events, } \\
\text { so that they can provide } \\
\text { training for new staff. } \\
\text { - It is important that new } \\
\text { staff understands their } \\
\text { responsibilities and has the } \\
\text { knowledge and skills to } \\
\text { deliver SNaP as intended. }\end{array}$ & On-going & After turnover events \\
\hline 14 & $\begin{array}{l}\text { Organize online booster } \\
\text { training session }\end{array}$ & $\begin{array}{l}\text { - The central } \\
\text { research } \\
\text { team } \\
\text { - Site leaders } \\
\text { and staff }\end{array}$ & $\begin{array}{l}\text { - Create booster training } \\
\text { content based on process } \\
\text { evaluation of sites } \\
\text { implementation of SNaP } \\
\text { - Create an online platform } \\
\text { and upload training } \\
\text { materials } \\
\text { - Provide access and } \\
\text { guidance to site staff to } \\
\text { learn through the online } \\
\text { training platform } \\
\text { - Participate in online booster } \\
\text { training (done by site staff) }\end{array}$ & $\begin{array}{l}\text { - The skills of system } \\
\text { navigators and counselors } \\
\text { are improved and their } \\
\text { weaknesses in } \\
\text { implementing SNaP are } \\
\text { addressed }\end{array}$ & $\begin{array}{l}\text { Two times } \\
\text { throughout } \\
\text { the study }\end{array}$ & $\begin{array}{l}6 \text { and } 14 \text { months } \\
\text { after implementation } \\
\text { of the first regional } \\
\text { training }\end{array}$ \\
\hline 15 & $\begin{array}{l}\text { Conduct group calls every } \\
6 \text { months by region or } \\
\text { province to share } \\
\text { experience and feedback }\end{array}$ & $\begin{array}{l}\text { - The central } \\
\text { research } \\
\text { team } \\
\text { - Site leaders } \\
\text { and staff }\end{array}$ & $\begin{array}{l}\text { - Facilitate group calls every } \\
6 \text { months for sites in the } \\
\text { same arm }\end{array}$ & $\begin{array}{l}\text { - Site staff knows how SNaP } \\
\text { is implemented at other } \\
\text { sites and have the platform } \\
\text { to share their knowledge } \\
\text { and experience }\end{array}$ & $\begin{array}{l}\text { Semi- } \\
\text { annually }\end{array}$ & $\begin{array}{l}\text { Every } 6 \text { months after } \\
\text { enrollment }\end{array}$ \\
\hline
\end{tabular}

*The central research team refers to the research team from the UNC Vietnam project in Hanoi, including the project management, leads of tailored approach and standard approach arm, project assistant, data assistant, and evaluation and management officer

${ }^{r}$ Actions are implemented by the central research team, unless otherwise specified

Abbreviations: ART antiretroviral therapy, CDC Center for Disease Control, HMU Hanoi Medical University, PWID people who inject drugs, SNaP system navigation and psychosocial counseling intervention, VAAC Vietnam Authority of HIV/AIDS Control

For tailored approach sites, the menu of strategies will be further tailored to the needs of each clinic.

\section{Standard approach}

We have developed a multifaceted implementation strategy that includes 15 "discrete" implementation strategies to be applied to the standard arm (Table 1). All strategies will be implemented by the central team, with appropriate collaboration with provincial Centers for Disease Control (CDC) leaders, site leaders, and site staff. Each strategy will be tracked throughout the implementation process by collecting information on the actors, actions, dose, timing of activities, and outcomes of the strategy [57].

\section{Tailored approach}

HIV testing sites in the tailored condition have access to the same implementation strategies developed for the standard arm. In addition, tailored approach sites will have access to a broader menu of additional strategies identified through the intervention mapping process. In order to explore site-specific targets for change that could be addressed through tailored implementation strategies, we will conduct an assessment of each of the 
Table 2 List of optional tailored implementation strategies

\begin{tabular}{ll}
\hline Strategy & Descriptiont \\
\hline Audit and feedback & $\begin{array}{l}\text { Collect and summarize SNaP implementation data over a specified time period and give it to leaders within } \\
\text { sites to monitor, evaluate, and modify SNaP activities }\end{array}$ \\
$\begin{array}{l}\text { Conduct cyclical small tests of } \\
\text { change }\end{array}$ & $\begin{array}{l}\text { Implement changes in SnaP implementation in a cyclical fashion using small tests of change before taking } \\
\text { changes system-wide. Tests of change benefit from systematic measurement, and results of the tests of change } \\
\text { are studied for insights on how to do better. This process continues serially over time, and refinement is added } \\
\text { with each cycle }\end{array}$ \\
$\begin{array}{l}\text { Conduct local needs assessment } \\
\text { Obtain and use participants and }\end{array}$ & $\begin{array}{l}\text { Collect and analyze data related to the local need for the innovation } \\
\text { Develop strategies to increase participants and family feedback on the implementation effort }\end{array}$
\end{tabular}

Organize implementation team meetings

Capture and share local knowledge

Shadow other experts

Facilitate relay of data to implementers

Remind implementers
Develop and support teams of staff who are implementing SNaP and give them protected time to reflect on the implementation effort, share lessons learned, and support one another's learning

Capture local knowledge from implementation sites on how site staff made something work in their setting and then share it with other sites

Provide ways for site staff to directly observe experienced system navigators and psychosocial counselors deliver $\mathrm{SNaP}$

Provide as close to real-time data as possible about key measures of process/outcomes using integrated modes/channels of communication in a way that promotes use of SNaP

Develop reminder systems designed to help site staff to recall information and/or prompt them to use the $\mathrm{SNaP}$ intervention

Non-monetary strategies to motivate site staff to implement SNaP (recognition, certificate, rewards, etc.)

Non-monetary incentives

\section{Outcomes}

21 sites in the tailored approach arm, using a structured online survey prior to implementation. Consistent with our guiding determinant framework (CFIR), we will assess inner setting factors that may influence implementation processes, including organizational readiness to change [54], implementation leadership [58], implementation climate [59], and available resources. We have developed a pre-determined list of additional strategies (Table 2) selected from the Expert Recommendations for Implementing Change (ERIC) menu-a relatively comprehensive list of implementation strategies suggested by stakeholders with expertise in implementation research, applied implementation, and clinical practice [60].

Through a hands-on 2-day intensive training session, we will work with these sites to tailor their implementation strategies to address their site-specific determinants of $\mathrm{SNaP}$ implementation. Tailored approach sites will decide which strategies to implement based on their own needs and capacity. In addition, provincial health officials and HIV testing sites in the tailored arm will receive resources and coaching to assist them in tailoring their implementation strategy to address key determinants of change throughout the implementation process. This additional coaching will be conducted through external phone assistance and regular calls with each tailored approach site to discuss site-specific challenges and assess ongoing implementation. If adjustment is needed, site-specific standard operating procedures will be updated by the site and reviewed centrally. These activities are presented as three mandatory additional strategies applied to tailored approach sites (strategies 16, 17, and 18 in Table 3).

\section{Implementation outcomes}

The primary implementation outcome is fidelity-the extent to which $\mathrm{SNaP}$ is delivered as intended. Fidelity will be measured at the test site level by assessing each site's success in completing the three protocol-specified sessions (two navigation, one counseling) within the required 8- or 4-week period, respectively, weighted by the central implementation team's quality rating of those sessions. Session completion will be assessed by reviewing the navigator and counselor logs, while session quality will be assessed by the central implementation team reviewing and scoring of a random $10 \%$ of all forms (navigation) and audio-recordings (psychosocial counseling). Central implementation teams will rate them on a 100-point quality scale from poor to excellent. Reviewers will be masked to the arm when reviewing navigation forms or audio-recordings.

$$
\begin{aligned}
\text { Fidelity } & =\% \text { navigation sessions completed } * \text { average quality score } \\
& +\% \text { counseling sessions completed } * \text { average quality score }
\end{aligned}
$$

Secondary implementation outcomes are penetration, acceptability, and implementation costs (Table 4).

\section{Effectiveness outcomes}

The primary effectiveness outcome is ART uptake among all enrolled PWID. ART uptake is defined as the proportion of participants receiving $\mathrm{SNaP}$ with evidence of an ART-related visit in an ART clinic. The secondary effectiveness outcomes include viral suppression and 
Table 3 Characteristics of tailored implementation strategies applied to all TA sites

\begin{tabular}{|c|c|c|c|c|c|c|}
\hline No. & Strategy & Actor(s) & Action ${ }^{\gamma}$ & Action target & Dose & Timing \\
\hline 16 & $\begin{array}{l}\text { Provide external } \\
\text { technical assistance } \\
\text { through the phone to } \\
\text { tailored approach sites }\end{array}$ & $\begin{array}{l}\text { - The } \\
\text { central } \\
\text { research } \\
\text { team* }\end{array}$ & $\begin{array}{l}\text { - Provide external technical } \\
\text { assistance through the phone to } \\
\text { tailored approach sites whenever } \\
\text { they need help with } \\
\text { implementing SNaP } \\
\text { - Document all requests for help } \\
\text { and support for tailored sites }\end{array}$ & $\begin{array}{l}\text { - Tailored approach sites receive the } \\
\text { continuous support they need to } \\
\text { implement SNaP well. } \\
\text { - All requests for help and the } \\
\text { support provided by the central } \\
\text { team are properly documented } \\
\text { throughout the study }\end{array}$ & On-going & As needed \\
\hline 17 & $\begin{array}{l}\text { Conduct 2-day, site- } \\
\text { specific training to dis- } \\
\text { cuss site-specific barriers } \\
\text { and develop implemen- } \\
\text { tation plan }\end{array}$ & $\begin{array}{l}\text { - The } \\
\text { central } \\
\text { research } \\
\text { team } \\
\text { - Site staff }\end{array}$ & $\begin{array}{l}\text { - Discuss with each site to prioritize } \\
\text { their specific barriers, facilitators, } \\
\text { and finalize the menu of potential } \\
\text { tailored strategies as well as } \\
\text { implementation plan } \\
\text { - Provide training on how to apply } \\
\text { these implementation strategies }\end{array}$ & $\begin{array}{l}\text { - Site-specific barriers and facilitators } \\
\text { to SNaP implementation are iden- } \\
\text { tified and prioritized based on } \\
\text { their importance } \\
\text { - Acceptable and feasible } \\
\text { implementation strategies to } \\
\text { overcome the barriers are } \\
\text { developed } \\
\text { - Sites have a clear and specific plan } \\
\text { to implement these strategies } \\
\text { once enrollment starts }\end{array}$ & $\begin{array}{l}\text { Once for } \\
\text { each } \\
\text { tailored } \\
\text { approach } \\
\text { site }\end{array}$ & $\begin{array}{l}\text { Before } \mathrm{SNaP} \\
\text { implementation, } \\
\text { after regional } \\
\text { training }\end{array}$ \\
\hline 18 & $\begin{array}{l}\text { Conduct monthly calls to } \\
\text { tailored approach sites } \\
\text { to provide continuing } \\
\text { support in implementing } \\
\text { SNaP }\end{array}$ & $\begin{array}{l}\text { - The } \\
\text { central } \\
\text { research } \\
\text { team } \\
\text { - Site staff }\end{array}$ & $\begin{array}{l}\text { - Monitor and track the } \\
\text { implementation of strategies } \\
\text { - Identify new barriers, facilitators } \\
\text { and work with sites to create new } \\
\text { implementation strategies if } \\
\text { needed }\end{array}$ & $\begin{array}{l}\text { - Progress of the implementation of } \\
\text { SNaP and implementation } \\
\text { strategies at sites is updated } \\
\text { regularly to the central research } \\
\text { team } \\
\text { - New barriers and appropriate } \\
\text { implementation strategies to } \\
\text { overcome these barriers at sites } \\
\text { are identified to improve the } \\
\text { implementation of SNaP } \\
\text { - The central research team } \\
\text { provides continuous support and } \\
\text { builds capacities for sites to } \\
\text { implement SNaP and other } \\
\text { interventions in the future }\end{array}$ & $\begin{array}{l}\text { Once a } \\
\text { month }\end{array}$ & $\begin{array}{l}\text { Every month } \\
\text { after enrollment }\end{array}$ \\
\hline
\end{tabular}

*The central research team refers to the research team from UNC Vietnam project, including the project management, leads of tailored approach and standard approach arm, project assistant, data assistant and evaluation and management officer rActions are implemented by the central research team, unless otherwise specified

MOUD uptake, assessed among the subsample cohort only (Table 4).

\section{Cost-effectiveness measurements}

We will conduct an empirical costing study of $\mathrm{SNaP}-\mathrm{in}$ cluding both approaches and the actual process of implementation itself-from a societal perspective. We will estimate implementation costs prospectively by embedding a trained costing specialist within each IM team, documenting all resources used (e.g., staff training level and time, travel costs, supplies, etc.) and estimating the unit cost of each resource. To estimate the unit health system cost of each intervention, we will perform detailed budgetary analysis including interviews of key staff, review of logbooks/timesheets, and time-and-motion studies to record navigator, counselor, and other staff time. To estimate patient costs, we will administer a survey to a smaller subset of the 1500participant cohort at baseline, 12 months, and 24 months to collect data on direct and indirect (lost wages, child care, etc.) costs of clinic visits and other elements (e.g., medication side effects) associated with ART, MOUD, and SNaP itself.

\section{High- and low-performing sites}

In HPTN 074, the Vietnam site achieved 86-88\% completion of navigation and counseling sessions in the protocol-specified window, and in our counseling studies, we consistently achieve 90-95\% quality scores on supervisor-rated counseling sessions [17]. Using the formula to calculate fidelity, a site completing $90 \%$ of navigation sessions with an $80 \%$ average quality score and $80 \%$ of counseling sessions with an $80 \%$ average quality score would receive a total score of 136 . Our a priori definition of successful implementation at 24 months is a site with a fidelity score of 136 out of 200 and 70\% ART uptake among its newly diagnosed or previously diagnosed and not currently on ART participants.

\section{Data collection and analysis}

Formative data collection and analysis (year 1, completed)

We are in year 2 of the study and will start enrollment in 2020. In study year 1, as part of the first step of IM, we conducted 2 rounds of focus group discussions among local stakeholders in Hanoi and Thai Nguyen. The first round explored potential structural barriers to 
Table 4 Study outcomes

\begin{tabular}{lll}
\hline Outcome & Definition & Measure or scale* $^{*}$ \\
\hline Primary implementation outcome & \\
$\begin{array}{ll}\text { Fidelity to SNaP } \\
\text { protocol }\end{array}$ & $\begin{array}{l}\text { Delivering SNaP as } \\
\text { intended }\end{array}$ & $\begin{array}{l}\text { \% system navigation } \\
\text { sessions completed } \times \\
\text { average quality score }+\% \\
\end{array}$ \\
& $\begin{array}{l}\text { counseling sessions } \\
\text { completed } \times \text { average quality } \\
\end{array}$ & score
\end{tabular}

Secondary implementation outcomes

Penetration $\quad \%$ of PWID participants
contacted, and

contacted, and enrolled in SNaP

Proportion of newly diagnosed or previously diagnosed and not currently on ART participants at HIV testing sites who are contacted by a navigator and/or counselor and participate in a SNaP session.

Acceptability

Perception that SNaP is For PWID participants: agreeable, palatable, or acceptability of Intervention satisfactory. Measure scale [61] For site staff: Ottawa Acceptability of Decision Rules Instrument [62] $\begin{array}{ll}\text { Implementation } & \text { Costs of } \mathrm{SNaP} \text { and its } \\ \text { costs } & \text { implementation }\end{array}$

Primary effectiveness outcome

Uptake of ART \% participants who initiated ART

ART clinic records of consenting participants

Secondary effectiveness outcomes

Viral suppression \% participants virally suppressed

Uptake of $\quad \%$ of participants on MOUD MOUD

Undetectable viral load on dried blood spots in the subsample cohort

MOUD clinic records of consenting participants

*All measures were adapted to SNaP (Additional file 2) Abbreviations: $A R T$ antiretroviral therapy, MOUD medications for opioid use disorder, PWID people who inject drugs, SNaP system navigation and psychosocial counseling intervention

and facilitators of $\mathrm{SNaP}$ implementation, while the second round discussed appropriateness and feasibility of proposed implementation strategies. During the preimplementation phase, we also conducted site initial assessments and site in-person visits. A simple initial survey was sent to sites to explore services provided, site's internet capacity and office space, staffing structure, current referral protocol, leadership strength, and other relevant characteristics. We also visit all sites to communicate with them in-person about the study and qualitatively evaluate the strength of leadership commitment at each site. After each visit, a brief qualitative description on leaders' engagement and willingness to participate in $\mathrm{SNaP}$ was created by the research team. The information and data collected were used for randomization and to inform feasibility of implementation strategies. We also developed a standardized form for collection of cost and resource-use data and have prospectively collected costs during the first year of the study, delineating these costs as research-related versus necessary for programmatic implementation, on a weekly basis.

\section{Data collection and analysis after intervention implementation (year 2-4)}

Quantitative data To compare two implementation approaches in Aim 1, interview data will be collected for both site staff and PWID participants (in the subsample cohort) at baseline, 12, and 24 months follow-up visits. Viral suppression data will also be collected for PWID participants in the subsample cohort. For ART and MOUD uptake data, each patient will have a second masked identification number, which is used to link with their records at HIV and methadone clinics. Only masked study identification numbers of participants will be used to extract information from ART and MOUD clinics to confirm ART initiation and MOUD uptake.

For the cost-effectiveness analysis in Aim 2, we will administer quantitative costing questionnaires for PWID participants randomly selected at each of 12 purposively selected sites (six per arm, selected for broad representation of geography, number of clients, and proportion of clients who are PWID) at baseline and 12-month followup visit. In addition, we have developed a quantitative costing tracker to document costing for study implementation at the above-site (central) level and questionnaires for assessment of implementation costs at all 42 sites.

For Aim 3, site characteristics will be assessed with exploratory analyses to examine associations with highand low-performing clinics. We will use a generalized linear model with a logit link and binomial error distribution to assess the dichotomous outcome of high or low performance.

Qualitative data As part of Aim 3, we will conduct six semi-structured in-depth interviews with PWID participants in 12 HIV testing sites (for both low- and highperforming sites in two arms at the 24-month follow-up visits). We will ask participants about barriers and facilitators to uptake of ART, ART adherence, MOUD uptake, attitudes, and experiences in the HIV test site and with navigators and counselors. In these same HIV testing sites, we will conduct semi-structured in-depth interviews with navigators/counselors, site staff, site directors, and HIV providers to understand their exposure to and perceptions of $\mathrm{SNaP}$ and to inform the context and processes that may underlie $\mathrm{SNaP}$ success and failures. All qualitative interviews will be audiotaped, transcribed, translated, coded, and computerized for analysis. Textual data analysis will involve reading for content, deductive 
and inductive coding, data display to identify emerging themes, data reduction, and interpretation. Responses of navigators and counselors, test site staff, and test site directors will be compared within and across the staff groups and high versus low performing sites. Finally, both qualitative and quantitative data will be combined and triangulated to understand $\mathrm{SNaP}$ and two approaches within high- and low-performing sites.

\section{Sample size \\ Implementation outcomes sample size calculations}

For the primary outcome of fidelity, using two-tailed tests with $\alpha=0.05$ and assuming a conservatively large standard deviation of 40,42 sites will give us $80 \%$ power to detect a difference between a fidelity score of 136 (high-performing site) in the tailored arm and 100.5 in the standard arm (corresponds to $75 \%$ session completion and $67 \%$ average quality ratings).

\section{Effectiveness outcomes sample size calculations}

We estimate that the intra-cluster correlation coefficient (ICC) may range from 0.01 to 0.05 , implying a design effect between 2.5 and 8.4 [63-66]. Using two-tailed tests and $\alpha=0.05$, a sample size of 6200 (available sample after accounting for $12 \%$ mortality) will have > $80 \%$ power to detect a difference as small as 10 percentage points (e.g., $70 \%$ vs. $60 \%$ ART uptake) if the ICC is as large as 0.05 , and as small as 6 percentage points (e.g., $70 \%$ vs. $64 \%$ ART uptake) if the ICC is as small as 0.01 . For viral load, which is based on a sample of $n=1200$ (available sample after accounting for $20 \%$ lost to followup), assuming the same ICC of $0.01-0.05$, we will have $80 \%$ power to detect differences of $10-14$ percentage points in viral suppression between arms.

\section{Discussion}

The HIV burden among PWID in low-resource settings will only be reduced when EBIs are effectively implemented at scale. To our knowledge, the proposed study will be the first to use IM to design a multifaceted implementation package for PWID at a national level. It will evaluate the best approach to identifying implementation strategies to scale up the $\mathrm{SNaP}$ intervention in a low-resource setting.

The lack of a systematic approach to developing implementation strategies can lead to failure to address determinants of implementation [67, 68]. More systematic and rigorous methods are recommended for the design and tailoring implementation strategies for EBIs, such as concept mapping, group model building, conjoint analysis, and IM [32]. In this study, to develop the standard implementation package, we used IM-a mixed-method framework that provides many advantages. Within the literature on tailoring implementation strategies, the approaches used to identify barriers to implementation vary widely [39]. We applied a mix of quantitative and qualitative methods, including focus group discussions and informal interviews with local stakeholders, quantitative assessments of sites' characteristics and implementation climate, and in-person site visits to explore potential barriers and facilitators to intervention implementation. In addition to IM, our tailored implementation approach allows for flexibility in developing strategies through a two-step local process: rapid assessment of implementation barriers and facilitators in each site; and selection of site-specific strategies using a preidentified menu of potential strategies to address barriers. Moreover, our continuous interactions with tailored approach sites through monthly calls will provide additional opportunities to communicate with sites about their specific needs and improve $\mathrm{SNaP}$ implementation.

This study addresses priorities in the field of implementation science in multiple ways:

- It is a true cluster randomized effectivenessimplementation trial: most HIV studies are individually randomized and/or measure effectiveness rather than implementation outcomes [69]. Our study will randomize at the site-level and will collect primary and secondary implementation outcomes at the sitelevel.

- It scales up a highly effective HIV intervention for PWID: few HIV trials for PWID have yielded such promising findings across multiple self-reported and biological outcomes as HPTN 074 [17]. Bringing a successful EBIs to scale with careful implementation assessment has the potential to curb the global PWID HIV epidemic.

- It assesses the role of HIV test site context for implementation: while IM has long emphasized the importance of implementation [25, 34, 35], using IM as a method to tailor implementation strategies has rarely been evaluated. The tailored approach allows site-level variables, such as readiness to change and implementation climate, to be addressed as implementation strategies are selected.

- It incorporates cost-effectiveness to inform policy makers in low-resource settings: even though economic evaluations help guide decision making regarding the allocation of resources to the implementation and scale-up of EBIs, they are not routinely done in implementation studies [41, 70]. This study allows for assessments of the incremental costs of the standard versus tailored approach to implementation. Moreover, our cost-effectiveness aim 
incorporates prospective, empirical costing of the full implementation process (including all aspects of IM), not just the intervention itself.

- It identifies site characteristics to inform future scale-up: the focus on test site-level predictors of successful implementation will be critical for scaleup efforts of EBIs. These data will provide insight into characteristics that influence successful EBI implementation among PWID, thereby informing governments' decisions about allocation of limited resources.

- It improves tracking and reporting of implementation strategies: poor reporting of implementation strategies makes it impossible to replicate effective strategies or learn from ineffective strategies $[25,28,57]$. To address these limitations, we will carefully track the agencies' use of implementation strategies using established methods $[71,72]$. We will also report the use of strategies using established guidelines [57], which will involve naming, defining, and specifying implementation strategies in sufficient detail to enable replication in other settings.

The biggest challenge to this study is the logistics of implementing a large, cluster randomized study in 10 different provinces across the country. This challenge has been alleviated by the collaboration of our welltrained and experienced permanent UNC-Vietnam study team and our implementing partners in HMU and VAAC, who will oversee implementation and provide technical assistance. A second concern is our ability to track PWID participants as they initiate ART and MOUD, due to the lack of adequate clinical records in Vietnam. We will reduce this concern by establishing effective communication between HIV testing sites and ART clinics, as well as using masked identification numbers to verify and match participants when reviewing clinical records.

\section{Conclusions}

In summary, PWID need impactful interventions to reduce their HIV-associated morbidity and mortality and slow the broader HIV epidemic. This implementation trial will provide critical guidance to policymakers worldwide who are responsible for reducing the burden of HIV infection among PWID. Regardless of the outcome, the trial will contribute to the field of implementation science through its examination of implementation and effectiveness outcomes, cost, and characterization HIV testing sites that successfully or unsuccessfully implement the intervention.

\section{Supplementary information}

Supplementary information accompanies this paper at https://doi.org/10. 1186/s13012-020-01020-z.

Additional file 1. SNaP checklists of study protocol.

Additional file 2. Measurement scales.

\section{Abbreviations}

ART: Antiretroviral therapy; CDC: Center for Disease Control;

CFIR: Consolidated Framework for Implementation Research; EBI: Evidencebased intervention; HMU: Hanoi Medical University; HPTN: HIV Prevention Trial Network; IM: Intervention mapping; MOUD: Medications for opioid use disorder; PWID: People who inject drugs; SNaP: Systems navigation and psychosocial counseling; UNC: University of North Carolina, Chapel Hill; VAAC: Vietnam Authority of HIV/AIDS Control

\section{Acknowledgements}

We would like to thank all staff in the SNaP central implementation team at the UNC Project Vietnam for their work in preparing and conducting this trial (Mrs Dang Thi Hong Linh, Nguyen Thanh Van, Le Thi Thu Trang, Tran Thi Van Anh, and Nguyen Thanh Van). We also thank provincial Centers for Diseases Control in the 10 provinces and local stakeholders participating in our focus group discussions for their significant guidance and support throughout the pre-implementation phase.

\section{Authors' contributions}

WM and VG conceived the study and obtained the funding, WM, VG, BJP, $M N, T S, H T, A C, A D$, and DD contributed to research design and protocol development. BJP helped conceptualize the intervention conditions, contributed to the grant writing, and informed all implementation materials. MN and AC drafted the manuscript, and VG, WM, BJP, TS, and HT revised it critically with important intellectual contents. All authors read and approved the final manuscript.

\section{Funding}

This study was supported by a grant from the National Institute of Drug Abuse (NIDA), 1R01DA047876-01. BJP was also supported by the National Institute of Mental Health through K01MH113806. KEL was also supported by the National Institute of Drug Abuse through K01DA048174.

\section{Availability of data and materials}

Data collection for this study is ongoing, so no data and materials are currently available.

\section{Ethics approval and consent to participate}

The study was approved by the Institutional Review Boards at the University of North Carolina, Chapel Hill and Hanoi Medical University.

\section{Consent for publication}

All participants provided written informed consent before participating in the study, which included consent to publish anonymous quotes from individual participants.

\section{Competing interests}

The authors declare that they have no competing interests.

\section{Author details}

${ }^{1}$ Department of Health Behavior, Gillings School of Global Public Health, 135 Dauer Dr, Chapel Hill, NC 27599, USA. ${ }^{2}$ Department of Epidemiology, Institute of Preventive Medicine and Public Health, 1 Ton That Tung St., Dong Da, Hanoi, Vietnam. ${ }^{3}$ University of North Carolina Project Vietnam, Lot E2 Duong Dinh Nghe St., Cau Giay, Hanoi, Vietnam. ${ }^{4}$ Brown School, Washington University in St. Louis, One Brookings Drive, St. Louis, MO 63130, USA ${ }^{5}$ Vietnam Authority of HIV/AIDS Control, Land 8 That Thuyet St., Ba Dinh, Hanoi, Vietnam. ${ }^{6}$ Department of Epidemiology, Johns Hopkins Bloomberg School of Public Health, 615 N Wolfe St, Baltimore, MD 21205, USA. ${ }^{7}$ Department of Health, Behavior and Society, Johns Hopkins Bloomberg School of Public Health, 615 N Wolfe St, Baltimore, MD 21205, USA. ${ }^{8}$ Department of Epidemiology, College of Public Health, Ohio State University, 250 Cunz Hall, 1841 Neil Ave, Columbus, OH 43210, USA. 
${ }^{9}$ Department of Epidemiology, Gillings School of Global Public Health, 135 Dauer Dr, Chapel Hill, NC 27599, USA. ${ }^{10}$ Division of Infectious Diseases, UNC School of Medicine, 321 S Columbia St, Chapel Hill, NC 27516, USA.

Received: 1 July 2020 Accepted: 8 July 2020

Published online: 08 August 2020

\section{References}

1. United Nations of Office on Drug and Crime. World Drug Report Booket 2: global overview of drug demand and supply. 2019.

2. Wandeler G, Johnson LF, Egger M. Trends in life expectancy of HIV-positive adults on antiretroviral therapy across the globe: comparisons with general population. Curr Opin HIV AIDS. 2016;11(5):492-500.

3. Vallecillo G, Robles MJ, Duran X, Lerma E, Horcajada JP, Torrens M. Trends in AIDS Mortality, Retention in Opioid Agonist Therapy, and HIV RNA Suppression in HIV-Infected People Who Injected Drugs from 2000 to 2015. AIDS Behav. 2018;22(9):2766-72.

4. Larney S, Peacock A, Leung J, Colledge S, Hickman M, Vickerman P, et al. Global, regional, and country-level coverage of interventions to prevent and manage HIV and hepatitis C among people who inject drugs: a systematic review. Lancet Glob Health. 2017;5(12):e1208-e20.

5. Boltaev AA, El-Bassel N, Deryabina AP, Terlikbaeva A, Gilbert L, Hunt T, et al. Scaling up HIV prevention efforts targeting people who inject drugs in Central Asia: a review of key challenges and ways forward. Drug Alcohol Depend. 2013;132(Suppl 1):S41-7.

6. Bridge J, Lazarus JV, Atun R. HIV epidemics and prevention responses in Asia and Eastern Europe: lessons to be learned? AIDS (London, England). 2010;24 Suppl 3:S86-S94.

7. Degenhardt L, Mathers BM, Wirtz AL, Wolfe D, Kamarulzaman A, Carrieri MP, et al. What has been achieved in HIV prevention, treatment and care for people who inject drugs, 2010-2012? A review of the six highest burden countries. The International journal on drug policy. 2014;25(1):53-60.

8. Strathdee SA, Shoptaw S, Dyer TP, Quan VM, Aramrattana A. Towards combination HIV prevention for injection drug users: addressing addictophobia, apathy and inattention. Curr Opin HIV AIDS. 2012;7(4):320-5.

9. UNAIDS. Vietnam Country factsheets. 2016.

10. Khuu NV, Nguyen TV, Tran HP, Nguyen PD, Vu TX, Tran T, et al. Viral load testing to monitor the HIV epidemic among PWID in Vietnam. Online J Public Health Inform. 2018;10(1):e198.

11. Nghiem VT, Bui TC, Nadol PP, Phan SH, Kieu BT, Kling R, et al. Prevalence and correlates of HIV infection among men who inject drugs in a remote area of Vietnam. Harm Reduct J. 2018;15(1):8.

12. Nguyen TMT, Tran BX, Fleming M, Pham MD, Nguyen LT, Nguyen ALT, et al. HIV knowledge and risk behaviors among drug users in three Vietnamese mountainous provinces. Subst Abuse Treat Prev Policy. 2019;14(1):3.

13. UNAIDS. 90-90-90: An ambitious treatment target to help end the AIDS epidemic. 2014

14. UNAIDS. Viet Nam is the first country in Asia to commit to new HIV treatment targets: UNAIDS; 2014 [Available from: https://www.unaids.org/ en/resources/presscentre/featurestories/2014/october/2014102 7 vietnamtargets

15. Hirsch JS, Giang LM, Parker RG, Duong LB. Caught in the middle: the contested politics of HIV/AIDS and health policy in Vietnam. J Health Polit Policy Law. 2015:40(1):13-40.

16. Vietnam Ministry of Health. Optimizing Viet Nam's HIV Response: An Investment Case. 2014

17. Miller WC, Hoffman IF, Hanscom BS, Ha TV, Dumchev K, Djoerban Z, et al. A scalable, integrated intervention to engage people who inject drugs in HIV care and medication-assisted treatment (HPTN 074): a randomised, controlled phase 3 feasibility and efficacy study. Lancet (London, England). 2018:392(10149):747-59.

18. Hardee K, Rottach E, Jolivet R, Kiesel R. The Policy Dimensions of Scaling Up Health Initiatives. Washington DC; 2012.

19. Barker PM, Reid A, Schall MW. A framework for scaling up health interventions: lessons from large-scale improvement initiatives in Africa. Implement Sci. 2016;11(1):12.

20. Proctor EK, Landsverk J, Aarons G, Chambers D, Glisson C, Mittman B. Implementation research in mental health services: an emerging science with conceptual, methodological, and training challenges. Admin Pol Ment Health. 2009;36(1):24-34
21. Dutta A, Wirtz AL, Baral S, Beyrer C, Cleghorn FR. Key harm reduction interventions and their impact on the reduction of risky behavior and HIV incidence among people who inject drugs in low-income and middleincome countries. Curr Opin HIV AIDS. 2012;7(4):362-8.

22. Gilchrist G, Swan D, Widyaratna K, Marquez-Arrico JE, Hughes E, Mdege ND, et al. A Systematic Review and Meta-analysis of Psychosocial Interventions to Reduce Drug and Sexual Blood Borne Virus Risk Behaviours Among People Who Inject Drugs. AIDS Behav. 2017;21(7):1791-811.

23. Lazarus L, Patel S, Shaw A, Leblanc S, Lalonde C, Hladio M, et al. Uptake of Community-Based Peer Administered HIV Point-of-Care Testing: Findings from the PROUD Study. PLoS One. 2016;11(12):e0166942.

24. Strathdee SA, Beletsky L, Kerr T. HIV, drugs and the legal environment. The International journal on drug policy. 2015;26 Suppl 1(0 1):S27-S32.

25. Powell BJ, Haley AD, Patel SV, Amaya-Jackson L, Glienke B, Blythe M, et al. Improving the implementation and sustainment of evidence-based practices in community mental health organizations: a study protocol for a matched-pair cluster randomized pilot study of the Collaborative Organizational Approach to Selecting and Tailoring Implementation Strategies (COAST-IS). Implementation Science Communications. 2020;1 (1):9.

26. Koorts H, Eakin E, Estabrooks P, Timperio A, Salmon J, Bauman A. Implementation and scale up of population physical activity interventions for clinical and community settings: the PRACTIS guide. Int J Behav Nutr Phys Act. 2018;15(1):51.

27. van der Wees PJ, Jamtvedt G, Rebbeck T, de Bie RA, Dekker J, Hendriks EJM. Multifaceted strategies may increase implementation of physiotherapy clinical guidelines: a systematic review. Australian Journal of Physiotherapy. 2008;54(4):233-41.

28. Powell BJ, Fernandez ME, Williams NJ, Aarons GA, Beidas RS, Lewis CC, et al. Enhancing the Impact of Implementation Strategies in Healthcare: A Research Agenda. Front Public Health. 2019;7:3.

29. Marlies Hulscher MW. Multifaceted Implementation Strategies. In: Michel Wensing RG, Jeremy Grimshaw, editor. Improving Patient Care: The Implementation of Change in Health Care, Third Edition: John Wiley \& Sons Ltd; 2020. p. 313-27.

30. Glasgow RE, Chambers D. Developing Robust, Sustainable, Implementation Systems Using Rigorous, Rapid and Relevant Science. Clinical and Translational Science. 2012;5(1):48-55.

31. Hull L, Athanasiou T, Russ S. Implementation Science: A Neglected Opportunity to Accelerate Improvements in the Safety and Quality of Surgical Care. Ann Surg. 2017;265(6):1104-12.

32. Powell BJ, Beidas RS, Lewis CC, Aarons GA, McMillen JC, Proctor EK, et al. Methods to Improve the Selection and Tailoring of Implementation Strategies. The journal of behavioral health services \& research. 2017:44(2): 177-94.

33. Colquhoun HL, Squires JE, Kolehmainen N, Fraser C, Grimshaw JM. Methods for designing interventions to change healthcare professionals' behaviour: a systematic review. Implement Sci. 2017:12(1):30.

34. Fernandez ME, ten Hoor GA, van Lieshout S, Rodriguez SA, Beidas RS, Parcel $\mathrm{G}$, et al. Implementation Mapping: Using Intervention Mapping to Develop Implementation Strategies. Front Public Health. 2019;7:158.

35. Fernandez ME, Gonzales A, Tortolero-Luna G, Partida S, Bartholomew LK Using intervention mapping to develop a breast and cervical cancer screening program for Hispanic farmworkers: Cultivando La Salud. Health Promot Pract. 2005;6(4):394-404.

36. Bartholomew Eldridge LKMC, Ruiter RAC, Fernández ME, Kok G, Parcel GS. Planning Health Promotion Programs: An Intervention Mapping Approach. 4th edition. San Francisco: Jossey-Bass, Inc; 2016.

37. Mittman BS. Implementation science in health care. In: Brownson RCCG, Proctor EK, editors. Dissemination and Implementation Research in Health: Translating Science to Practice. New York: Oxford University Press; 2012. p. 400-18.

38. Baker R, Camosso-Stefinovic J, Gillies C, Shaw EJ, Cheater F, Flottorp S, et al. Tailored interventions to overcome identified barriers to change: effects on professional practice and health care outcomes. The Cochrane database of systematic reviews. 2010;3:Cd005470.

39. Baker R, Camosso-Stefinovic J, Gillies C, Shaw EJ, Cheater F, Flottorp S, et al. Tailored interventions to address determinants of practice. The Cochrane database of systematic reviews. 2015;4:Cd005470.

40. Roberts SLE, Healey A, Sevdalis N. Use of health economic evaluation in the implementation and improvement science fields - a systematic literature review. Implement Sci. 2019;14(1):72. 
41. Reeves P, Edmunds K, Searles A, Wiggers J. Economic evaluations of public health implementation-interventions: a systematic review and guideline for practice. Public Health. 2019;169:101-13.

42. Pinnock H, Barwick M, Carpenter CR, Eldridge S, Grandes G, Griffiths CJ, et al. Standards for Reporting Implementation Studies (StaRI) Statement. BMJ (Clinical research ed). 2017:356:16795.

43. Schulz KF, Altman DG, Moher D. CONSORT 2010 Statement: updated guidelines for reporting parallel group randomised trials. BMJ (Clinical research ed). 2010;340:c332.

44. Proctor $E$, Silmere $H$, Raghavan $R$, Hovmand $P$, Aarons G, Bunger A, et al. Outcomes for implementation research: conceptual distinctions, measurement challenges, and research agenda. Admin Pol Ment Health. 2011;38(2):65-76.

45. Damschroder L, Aron DC, Keith RE, Kirsh SR, Alexander JA, Lowery JC. Fostering implementation of health services research findings into practice: a consolidated framework for advancing implementation science. Implementation science : IS. 2009;4:50.

46. Nilsen P. Making sense of implementation theories, models and frameworks. Implementation science : IS. 2015;10:53.

47. Lash SJ, Timko C, Curran GM, McKay JR, Burden JL. Implementation of evidence-based substance use disorder continuing care interventions. Psychology of addictive behaviors : journal of the Society of Psychologists in Addictive Behaviors. 2011;25(2):238-51.

48. Helfrich CD, Weiner BJ, McKinney MM, Minasian L. Determinants of implementation effectiveness: adapting a framework for complex innovations. Medical care research and review : MCRR. 2007;64(3):279-303.

49. Lau R, Stevenson F, Ong BN, Dziedzic K, Treweek S, Eldridge S, et al. Achieving change in primary care--causes of the evidence to practice gap: systematic reviews of reviews. Implementation science : IS. 2016;11:40.

50. Guerrero EG, Fenwick K, Kong Y. Advancing theory development: exploring the leadership-climate relationship as a mechanism of the implementation of cultural competence. Implementation science : IS. 2017;12(1):133.

51. Patel B, Usherwood T, Harris M, Patel A, Panaretto K, Zwar N, et al. What drives adoption of a computerised, multifaceted quality improvement intervention for cardiovascular disease management in primary healthcare settings? A mixed methods analysis using normalisation process theory. Implementation science : IS. 2018;13(1):140.

52. Curran GM, Bauer M, Mittman B, Pyne JM, Stetler C. Effectivenessimplementation hybrid designs: combining elements of clinical effectiveness and implementation research to enhance public health impact. Med Care. 2012;50(3):217-26.

53. Vietnam Ministry of Health. National Guidelines on HIV testing. 2018.

54. Shea CM, Jacobs SR, Esserman DA, Bruce K, Weiner BJ. Organizational readiness for implementing change: a psychometric assessment of a new measure. Implement Sci. 2014;9(1):7.

55. Ehrhart MG, Aarons GA, Farahnak LR. Assessing the organizational context for EBP implementation: the development and validity testing of the Implementation Climate Scale (ICS). Implement Sci. 2014;9(1):157.

56. Lancaster KE, Miller WC, Kiriazova T, Sarasvita R, Bui Q, Ha TV, et al. Designing an Individually Tailored Multilevel Intervention to Increase Engagement in HIV and Substance Use Treatment Among People Who Inject Drugs With HIV: HPTN 074. AIDS education and prevention : official publication of the International Society for AIDS Education. 2019;31(2):95-110.

57. Proctor EK, Powell BJ, McMillen JC. Implementation strategies: recommendations for specifying and reporting. Implementation science : IS. 2013;8:139.

58. Aarons GA, Ehrhart MG, Farahnak LR. The implementation leadership scale (ILS): development of a brief measure of unit level implementation leadership. Implement Sci. 2014;9(1):45.

59. Weiner BJ, Belden CM, Bergmire DM, Johnston M. The meaning and measurement of implementation climate. Implementation science : IS. 2011;6:78.

60. Powell BJ, Waltz TJ, Chinman MJ, Damschroder LJ, Smith JL, Matthieu MM, et al. A refined compilation of implementation strategies: results from the Expert Recommendations for Implementing Change (ERIC) project. Implement Sci. 2015;10(1):21.

61. Weiner BJ, Lewis CC, Stanick C, Powell BJ, Dorsey CN, Clary AS, et al. Psychometric assessment of three newly developed implementation outcome measures. Implement Sci. 2017;12(1):108.

62. Brehaut JC, Graham ID, Wood TJ, Taljaard M, Eagles D, Lott A, et al. Measuring acceptability of clinical decision rules: validation of the Ottawa acceptability of decision rules instrument (OADRI) in four countries. Medical decision making : an international journal of the Society for Medical Decision Making. 2010;30(3):398-408.

63. Smeeth L, Ng ES. Intraclass correlation coefficients for cluster randomized trials in primary care: data from the MRC Trial of the Assessment and Management of Older People in the Community. Control Clin Trials. 2002; 23(4):409-21.

64. Parker DR, Evangelou E, Eaton CB. Intraclass correlation coefficients for cluster randomized trials in primary care: the cholesterol education and research trial (CEART). Contemporary clinical trials. 2005;26(2):260-7.

65. Pals SL, Beaty BL, Posner SF, Bull SS. Estimates of intraclass correlation for variables related to behavioral HIV/STD prevention in a predominantly African American and Hispanic sample of young women. Health education \& behavior : the official publication of the Society for Public Health Education. 2009;36(1):182-94.

66. Eldridge SM, Ashby D, Feder GS, Rudnicka AR, Ukoumunne OC. Lessons for cluster randomized trials in the twenty-first century: a systematic review of trials in primary care. Clinical trials (London, England). 2004;1(1):80-90.

67. Aarons GA, Hurlburt M, Horwitz SM. Advancing a Conceptual Model of Evidence-Based Practice Implementation in Public Service Sectors. Adm Policy Ment Health Ment Health Serv Res. 2011;38(1):4-23.

68. Flottorp SA, Oxman AD, Krause J, Musila NR, Wensing M, Godycki-Cwirko M, et al. A checklist for identifying determinants of practice: A systematic review and synthesis of frameworks and taxonomies of factors that prevent or enable improvements in healthcare professional practice. Implement Sci. 2013;8(1):35

69. Benbow N, Smith JD. Landscape of NIH-funded HIV Implementation Research: Preliminary Results of a Scoping Review. HIV Implementation Science Workshop. Chicago, Illinois: Third Coast CFAR in Chicago, Johns Hopkins University CFAR; 2018.

70. Hoomans T, Severens JL. Economic evaluation of implementation strategies in health care. Implement Sci. 2014;9(1):168.

71. Boyd MR, Powell BJ, Endicott D, Lewis CC. A Method for Tracking Implementation Strategies: An Exemplar Implementing Measurement-Based Care in Community Behavioral Health Clinics. Behav Ther. 2017.

72. Bunger AC, Powell BJ, Robertson HA, MacDowell H, Birken SA, Shea C. Tracking implementation strategies: a description of a practical approach and early findings. Health research policy and systems. 2017;15(1):15.

\section{Publisher's Note}

Springer Nature remains neutral with regard to jurisdictional claims in published maps and institutional affiliations.

\section{Ready to submit your research? Choose BMC and benefit from:}

- fast, convenient online submission

- thorough peer review by experienced researchers in your field

- rapid publication on acceptance

- support for research data, including large and complex data types

- gold Open Access which fosters wider collaboration and increased citations

- maximum visibility for your research: over $100 \mathrm{M}$ website views per year

At BMC, research is always in progress.

Learn more biomedcentral.com/submissions 